\title{
Hubungan Motivasi dengan Perilaku Ibu Post Partum dalam Melakukan Mobilisasi Dini
}

\author{
Relation of Motivation with Post Partum Mother's Behavior \\ in Early Mobilization
}

\author{
Ferilia Adiesti* \\ Program Studi D-III Kebidanan, Sekolah Tinggi Ilmu Kesehatan Majapahit \\ Jl. Raya Gayaman Km. 02 Mojoanyar, Mojokerto, Jawa Timur \\ *Corresponding author : f.adiesti_april86@yahoo.co.id
}

Received: February 30, 2019; Revise: April 15, 2019; Accepted: May 7, 2019

DOI: https://doi.org/10.31001/biomedika.v12i1.406

\begin{abstract}
ABSTRAK
Perdarahan Pasca persalinan merupakan salah satu penyebab kematian pada ibu. Yang mana penyebab terbanyak dari perdarahan pasca persalinan tersebut $50-60 \%$ karena kelemahan otot atau tidak adanya kontraksi uterus. Hal ini bias disebabkan karena ibu post partum tidak melakukan mobilisasi dini pasca bersalin normal 24 jam pertama setelah proses persalinan dan hari-hari berikutnya. Rancang bangun analitik - cross sectional. Jumlah sampel sebanyak 28 orang dan teknik pengambilan sampel consecutive sampling. Variabel independen adalah motivasi ibu post partum melakukan mobilisasi dini, sedangkan variabel dependentnya adalah perilaku ibu post partum dalam melakukan mobilisasi dini, pengumpulan data dengan menggunakan kuesioner. Berdasarkan hasil penelitian bahwa lebih dari 50\% responden (60\%) tidak termotivasi dalam melakukan mobilisasi dini, paling banyak perilaku ibu post partum melakukan mobilisasi dini adalah kurang sebanyak t orang (48\%). Hasil uji wilcoxon didapatkan bahwa $\alpha$ hitung lebih kecil dari $\alpha$ tabel yaitu $0,000<0,05$, artinya ada hubungan antara motivasi dengan perilaku ibu dalam melakukan mobilisasi dini. Diharapkan bidan dapat memberikan informasi tentang mobilisasi dini dengan menerapkan langsung dan juga membantu ibu post partum dalam melakukan mobilisasi dini sehingga ibu post partum tidak takut untuk melakukan mobilisasi dini.
\end{abstract}

Kata Kunci : motivasi; ibu post partum; perilaku; mobilisasi dini

\section{ABSTRACT}

Bleeding Post-delivery is one of the causes of death in the mother. Which is the most common cause of postpartum bleeding is 50-60\% due to muscle weakness or absence of uterine contractions. This can be caused because post partum mothers do not carry out early postpartum mobilization in the first 24 hours after labor and the following days. Analytical design - cross sectional. The number of samples was 28 people and the sampling technique was consecutive sampling. The independent variable is the motivation of post partum mothers to do early mobilization, while the dependent variable is the behavior of post partum mothers in conducting early mobilization, collecting data using a questionnaire. Based on the results of the study that more than 50\% of respondents (60\%) were not motivated in conducting early mobilization, at most the behavior of post partum mothers 
doing early mobilization was less than 12 people (48\%). The Wilcoxon test results showed that $\alpha$ was smaller than a table is 0,000<0,05, meaning that there is a relationship between motivation and maternal behavior in carrying out early mobilization. It is expected that midwives can provide information about early mobilization by applying directly and also helping post partum mothers in early mobilization so that post partum mothers are not afraid to carry out early mobilization.

Keywords: motivation; mother post partu; behavior; earlymobilization

\section{PENDAHULUAN}

Persalinan merupakan proses yang melelahkan itulah mengapa ibu disarankan agar tidak turun dari tempat tidur secara langsung setelah melahirkan karena dapat menyebabkan ibu pingsan akibat sirkulasi darah yang belum lancar, namun setelah istirahat 8 jam mobilisasi sangat perlu agar tidak terjadi pembengkakan akibat tersumbatnya pembuluh darah (Nakita, 2007). Mobilisasi dini adalah aktifitas yang dilakukan segera setelah beberapa jam dengan beranjak dari tempat tidur ibu bersalin normal. Ibu dianjurkan untuk melakukan latihan-latihan tertentu untuk memulihkan kembali jaringan penunjang otot genetalia, melakukan aktifitas fisik akan mempengaruhi kebutuhan otot terhadap oksigen yang mana kebutuhan akan meningkat berarti melancarkan aliran darah seperti halnya otot rahim, kontraksi uterus semakin baik, pengeluaran lochea menjadi lancar sehingga mempengaruhi proses pengecilan uterus (Manuaba, 2002).

Di Eropa pada tahun 2002 terdapat sekitar $25-50 \%$ kematian terjadi pada ibu 24 jam post partum. Di negara maju AKI pertahun hanya 27 per 100.000 kelahiran hidup, sedangkan di negara berkembang AKI rata-rata 18 kali lebih tinggi yaitu mencapai 480 per 100.000 kelahiran hidup. Ini disebabkan di negara berkembang, hampir $70 \%$ persalinan di lakukan secara operasi, sehingga ibu takut untuk melakukan mobilisasi dini pada 24 jam post partum (Syamsul, 2003). Mobilisasi dini sangat penting dalam rangka membantu proses involusi dan mengurangi risiko kejadian yang dapat memperburuk kondisi pada saat nifas seperti perdarahan, sub involusi uterus dan lain sebagainya (Winkjosastro, 2004).

Berdasarkan Survey Demografi dan Kesehatan Indonesia (SDKI) tahun 2008 bahwa Angka Kematian Ibu (AKI) di Indonesia masih berada pada angka 240 per 100.000 kelahiran hidup atau setiap jam terdapat 1 orang ibu post partum meninggal dunia. Sebab langsung kematian ibu berasal dari kejadian perdarahan 30\%, eklamsia $25 \%$, dan infeksi $12 \%$. Untuk kejadian perdarahan pada masa nifas selain disebabkan oleh kejadian akibat proses persalinan juga disebakan oleh kurangnya mobilisasi dini pada masa nifas (Depkes, 2008).

Badan Pusat Statistik (BPS) di Jawa Timur mencatat angka kematian ibu (AKI) menurun dari 334 tiap 100.000 kelahiran hidup tahun 1997 menjadi 262 setiap 100.0000 tahun 2005, 32\% diantaranya disebabkan oleh infeksi pada masa nifas meliputi bendungan payudara $9 \%$, perdarahan kala nifas $7 \%$, infeksi jalan lahir $7 \%$, mastitis $6 \%$, dan sub involusi uterus 3\%. Walaupun angka kematian ibu 
mengalami penurunan, tetapi angka tersebut masih tergolong tinggi dari target pemerintah yaitu 70 tiap 100.000 kelahiran hidup. Oleh karena itu, Gubernur Jawa Timur menghimbau kepada seluruh bidan dan petugas kesehatan untuk memberikan pelayanan yang optimal (Dinkes Jatim, 2008).

$$
\text { Dampak tidak melakukan }
$$

mobilisasi dini yang terjadi diantaranya adalah perdarahan post partum menurut hasil penelitian Wiknjosastro yang dikutip oleh Mochtar (2002) perdarahan merupakan salah satu sebab utama kematian ibu dalam perinatal yakni 5 $15 \%$ dari seluruh persalinan. Penyebab terbanyak dari perdarahan tersebut 50 $60 \%$ karena kelemahan otot atau tidak adanya kontraksi uterus. Hal ini disebabkan karena ibu post partum tidak melakukan mobilisasi dini pasca bersalin normal 24 jam pertama setelah proses persalinan dan hari-hari berikutnya. Mobilisasi dini dapat menghindarkan ibu post partum dari masalah-masalah yang timbul pasca persalinan. Upaya yang dilakukan pemerintah dalam meningkatkan mobilisasi dini pada ibu post partum adalah dengan meningkatkan mutu pelayanan dibidang kesehatan. (Diana, 2007).

Motivasi sangat penting dalam diri seseorang karena berpengaruh dalam perilaku ibu untuk melakukan sesuatu sehingga mencapai hasil tujuan tertentu. Mobilisasi dini masa nifas 24 jam post partum seperti miring ke kiri - ke kanan, duduk, berdiri dan berjalan dapat mempercepat proses pemulihan otot-otot genetalia. Jadi jelas bahwa perilaku yang timbul pada diri seseorang di dorong oleh adanya motivasi (Wahjosumidjo, 2006).
Berdasarkan studi awal dilakukan oleh peneliti dengan wawancara didapatkan tanggapan dari 4 dari 5 ibu bahwa ibu tidak melakukan mobilisasi dini setelah 2-6 jam post partum dikarenakan masih merasa sakit, pusing dan kurangnya pengetahuan mengenai mobilisasi dini dan data yang diperoleh dari buku register Puskesmas Likupang timur dari bulan JanuariSeptember 2014 terdapat 15 kasus dengan presentase penyebab terjadi resiko kematian ibu adalah Pendarahan (43,7\%), Preeklamsi (25\%), Infeksi (12,5\%), Abortus (6,25\%), dan lain-lain (12,5\%) dan juga terdapat ada 3 kasus post nifas yang dirujuk di Rumah sakit dengan presentase $2(66 \%)$ dengan pendarahan dan 1 (34\%) dengan infeksi ( Profil Puskesmas Likupang timur, 2014).

Dan dapat dilihat pada penelitian juga berdasarkan penelitian yang dilakukan oleh wira ditya $\mathrm{dkk}$, disebutkan terdapat hubungan yang bermakna antara mobilisasi dini dan proses penyembuhan luka pasca laparatomi $(p=0,003)$. Pasien mobilisasi dini dengan penyembuhan luka yang baik sebanyak 14 responden $(77,8 \%)$ dan buruk 4 responden (22,2\%). Responden tanpa mobilisasi dini dengan penyembuhan luka yang baik berjumlah 3 responden $(23,1 \%)$, sedangkan yang buruk 10 responden $(76,9 \%)$. dan kita, dapat menyimpulkan bahwa terdapat hubungan antara mobilisasi dini dengan proses penyembuhan luka pasien pasca laparatomi di bangsal bedah pria dan wanita RSUP Dr M. Djamil Padang. 


\section{METODE PENELITIAN}

Desain penelitian Analitik yaitu suatu rancangan penelitian yang digunakan untuk mencari hubungan sebab akibat dengan adanya keterlibatan penelitian dalam melakukan manipulasi terhadap variabel bebas. Jenis penelitian yang digunakan adalah Cross sectional, yang merupakan rancangan penelitian dengan melakukan pengukuran atau pengamatan pada saat bersamaan (sekali waktu) antara kedua variabel .

Variabel independen dalam penelitian ini adalah motivasi ibu post partum dalam melakukan mobilisasi dini. Variabel dependent dalam penelitian ini adalah perilaku ibu post partum dalam melakukan Mobilisasi dini. Penelitian ini pengambilan sampel secara consecutive sampling.

\section{HASIL DAN PEMBAHASAN}

Distribusi Frekuensi Pendidikan Responden. Berdasarkan Tabel 1 terlihat bahwa sebagian besar pendidikan responden adalah SD sebanyak 14 orang $(50 \%)$.

Tabel 1. Distribusi Frekuensi Pendidikan Responden

\begin{tabular}{|c|c|c|c|}
\hline No & Pendidikan & Jumlah & $(\%)$ \\
\hline 1. & Tidak tamat sekolah & 2 & 7,1 \\
\hline 2. & SD & 14 & 50 \\
\hline 3. & SLTP & 4 & 14,3 \\
\hline 4. & SLTA & 6 & 21,4 \\
\hline \multirow[t]{2}{*}{5.} & Akademi/Sarjana & 2 & 7,1 \\
\hline & Total & 28 & 100 \\
\hline
\end{tabular}

Distribusi Frekuensi Umur Responden. Berdasarkan Tabel 2 terlihat bahwa umur responden sebagian besar adalah $20-25$ tahun sebanyak 11 responden $(39,3 \%)$.

Tabel 2. Distribusi Frekuensi Umur Responden

\begin{tabular}{|c|c|c|c|}
\hline No & Umur (th) & Jumlah & $(\%)$ \\
\hline 1. & $20-25$ & 11 & 39,3 \\
\hline 2. & $26-30$ & 9 & 32,1 \\
\hline 3. & $31-35$ & 6 & 21,4 \\
\hline 4. & $>35$ & 2 & 7,1 \\
\hline & Total & 28 & 100 \\
\hline
\end{tabular}

Distribusi Frekuensi Pekerjaan Responden. Berdasarkan Tabel 3 terlihat bahwa sebagian besar responden tidak bekerja sebanyak 20 responden $(71,4 \%)$.

Tabel 3. Distribusi $\quad$ Frekuensi Pekerjaan Responden

\begin{tabular}{llcc}
\hline No & Pekerjaan & Jumlah & $\mathbf{( \% )}$ \\
\hline 1. & Petani & 1 & 3,6 \\
2. & Swasta & 4 & 14,3 \\
3. & PNS & 3 & 10,7 \\
4. & Tidak & 20 & 71,4 \\
& bekerja & & \\
\hline & Total & 28 & 100 \\
\hline
\end{tabular}

Sumber : Data Primer

Distribusi Frekuensi Jumlah Anak Responden. Berdasarkan Tabel 4 terlihat bahwa sebagian besar responden primipara sebanyak 16 responden $(57,1 \%)$.

Tabel 4. Distribusi Frekuensi Jumlah Anak Responden

\begin{tabular}{llcc}
\hline No & Jumlah Anak & Jumlah & $\mathbf{( \% )}$ \\
\hline 1. & Primipara & 16 & 57,1 \\
2. & Multipara & 10 & 35,7 \\
3. & Grandemultipara & 2 & 7,1 \\
\hline & Total & 28 & 100 \\
\hline
\end{tabular}

Sumber : Data Primer 
Tabel 5 ditunjukkan bahwa untuk yang termotivasi dan melakukan adalah sejumlah 23 (82\%). Hal tersebut sesuai bahwa motivasi merupakan Dorongan untuk bertindak demi mencapai suatu tujuan juga terwujud dalam bentuk perilaku.Maka dengan adanya motivasi dari orang terdekat dapat mengubah perilaku yang mna hal ini mau melakukan mobilisasi dini untuk membantu involusi pasca melahirkan. Hasil uji wilcoxon dengan SPSS didapatkan bahwa $\alpha$ hitung lebih kecil dari $\alpha$ tabel yaitu $0,000<0,05$, artinya ada hubungan antara motivasi dengan perilaku ibu dalam melakukan mobilisasi dini.

Tabel 5. Distribusi Frekuensi Motivasi Ibu terhadap mobilisasi dini

\begin{tabular}{lccccc}
\multicolumn{5}{c}{ Motivasi } \\
\hline Melakukan & $\%$ & Tidak Melakukan & $\%$ & Jumlah & $\%$
\end{tabular}

\section{Motivasi}

\begin{tabular}{lcccccc}
\hline Termotivasi & 23 & 82 & 5 & 18 & 28 & 100 \\
Tidak Termotivasi & 8 & 18 & 20 & 82 & 28 & 100 \\
\hline
\end{tabular}

\section{Sumber : Data Primer}

Menurut Upoy dan Sumantri (2001) mengatakan bahwa dorongan dari diri sendiri dan lingkungan sangat berpengaruh terhadap motivasi. Hasil analisis diketahui bahwa motivasi akan mempengaruhi perilaku ibu dalam melakukan mobilisasi dini. Hal tersebut terbukti dari hasil penelitian bahwa responden dengan motivasi tinggi mka mereka akan melakukan mobilisasi jika dibandingkan dengan responden yg motivasinya rendah. Motivasi yang dimiliki oleh ibu sangat berpengaruh terhadap pelaksanaan mobilisasi dini secara mandiri. Informasi yang dibrikan oleh petugas kesehatan jika tidak diikuti dengan motivasi yang baik membuat ibu akan tetap memiliki ketergantungan kepada petugas kesehatan daam mobilisasi dini. Penelitian ini pernah dilakukan sebelumnya oleh Nurfitriani (2017) tentang pengetahuan dan motivasi ibu post sectio caesarea dalam mobilisasi dini terdapat hubungan antara motivasi dengan ibu dalam melakukan mobilisasi dini dengan hasil 34 responden lebih dari setengah ibu memiliki motivasi yang tinggi yaitu sebanyak 18 responden (52,9\%), 10 dari 18 responden melakukan mobilisasi dini adalah supaya bisa segera pulang kerumah dan mengurus anak, berharap cepat sembuh, merasa sakit berkurang jika melakukan mobilisasi dini. Hasil analisis diperoleh dari 16 respoden $(47,1 \%)$ dengan motivasi rendah. Responden melakukam mobilisasi dini dengan bantuan perawat untuk melakukan mobilisasi secara bertahap. Rekomendasi dari penelitian ini adalah bahwa Ibu Post Partmul ebih meningkatkan pengetahuan tentang manfaat melakukan mobilisasi dini sehingga ibu termotivasi untuk melakukan mobilisasi dini. Rekomendasi yang lain bahwa bidan dapat memberikan informasi tentang mobilisasi dini dengan menerapkan langsung dan juga membantu ibu post partum dalam melakukan mobilisasi dini sehingga ibu post partum tidak takut untuk melakukan mobilisasi dini,mengajarkan ibu mulai dari (mika miki, duduk, berdiri, berjalan). 


\section{KESIMPULAN}

Penelitian menunjukkan bahwa lebih dari $50 \%$ responden $(60 \%)$ tidak termotivasi dalam melakukan mobilisasi dini. Separuh $(50 \%)$ perilaku ibu post partum melakukan mobilisasi dini adalah kurang sebanyak 10 orangHasil uji wilcoxon dengan SPSS didapatkan bahwa $\alpha$ hitung lebih kecil dari $\alpha$ tabel yaitu $0,000<0,05$, artinya ada hubungan antara motivasi dengan perilaku ibu dalam melakukan mobilisasi dini.

\section{DAFTAR PUSTAKA}

Ditya. 2016. Hubungan Mobilisasi Dini dengan Proses Penyembuhan Luka pada Pasien Pasca Laparatomi di Bangsal Bedah Pria dan Wanita RSUP Dr. M. Djamil Padang. Jurnal Kesehatan Andalas 5(3): 724 - 729.

Hidayat. 2003. Metode Penelitian Kebidanan. PT. Rineka Cipta: Jakarta.

Hidayat. 2007. Metode Penelitian Kebidanan. PT. Rineka cipta: Jakarta.

Marfuah, I. 2012. Hubungan Tingkat Pengetahuan dengan Sikap Ibu dalam Mobilisasi Dini Pasca Sectio Caesarea di Rumah Sakit Umum Daerah Dr. Moewardi. Naskah
Publikasi. Fakultas Ilmu Kesehatan. Universitas Muhammadiyah Surakarta.

Milka, M.V., Hasifah., \& Suryani, S. 2013. Hubungan Pengetahuan dan Sikap Ibu Post Partum Terhadap Mobilisasi Dini di RSIA Pertiwi Makassar.

http://elibrary_stikes_nani_hasanuddin-472-1-431428621.pdf

Nazir. 2005 Metode Penelitian. Bogor: Ghalia Indonesia

Nurfitriani. 2017. Pengetahuan Dan Motivasi Ibu Post Sectio Caesarea Dalam Mobilisasi Dini. Jurnal Psikologi Jambi 2(2): 31-38.

Nursalam. 2003. Konsep Penerapan Metodologi Penelitian Ilmu Keperawatan. Salemba Medika. Jakarta

Poerwodarminta. 2003. Kamus Besar Bahasa Indonesia. Jakarta.

Purwanto. 2004. Motivasi. Jakarta.

Sarwono. 2005. Ilmu Kebidanan. Yogyakarta: Yayasan Bina Pustaka Sarwono Prawiroharjo.

Sarwono. 2002. Ilmu Kebidanan. Yogyakarta: Yayasan Bina Pustaka Prawiriharjo.

Sulasmi. 2015. Hubungan Tingkat Pengetahuan Mobilisasi Dini Dengan Perilaku Mobilisasi Dini Post Partum Sc di RS PKU Muhammadiyah Yogyakarta. Naskah Publikasi. UNISA. Yogyakarta.

Wahjosumidjo. 2006. Prilaku dan Motivasi Jakarta: Yayasan Bina Pustaka Sarwono Prawiroharjo.

Winkjosastro. 2002. Ilmu Kandungan. Yogyakarta:

Yayasan Bina Pustaka Sarwono Prawiroharjo. 